\title{
The United Nations
}

University

\section{INTECH}

Institute for New Technologies

Discussion Paper Series

\#9707

Inter-Firm Technological Cooperation: Effects of Absorptive

Capacity, Firm-Size and Specialization

\author{
Frederico Rocha
}

December 1997 


\title{
Inter-Firm Technological Cooperation: Effects of Absorptive Capacity, Firm-Size and Specialization*
}

\begin{abstract}
$\underline{\text { Abstract }}$
This paper aims to add evidence on the role played by firms' technological competencies in the determination of their intensity of cooperation with other firms. Using a database composed by patents jointly filed by two or more firms in the European Patent Office, the paper: (i) finds no support for the hypothesis that in order for firms to increase their rate of cooperation they should expand their R\&D expenditures; (ii) holds that technological cooperation is explained by the need of the firm to acquire complementary competencies; (iii) concludes that cooperation is an alternative technological strategy for those firms that have adopted lean production to overcome obstacles posed by the cross-fertilization of technological fields; (iv) shows that Japanese firms have a higher level of cooperation than Western ones. This latter feature may be explained by the Japanese firm's greater level of productive specialization.
\end{abstract}

JEL Classification: L22; O32

Key Words: Technological Cooperation; Technological Strategies; Competence Building

\footnotetext{
* This paper was mostly written during the author's stay at UNU/INTECH. The author is grateful for the financial help provided by funded by UNDP. The paper has benefited from comments made by Nagesh Kumar, Pari Patel and the participants of the UNU/INTECH internal seminar. The usual dismissals apply.
} 


\section{Inter-Firm Technological Cooperation: Effects of Absorptive Capacity, Firm-Size and Specialization}

\section{INTRODUCTION}

Recent empirical and historical studies have demonstrated that new developments in technology, such as cross-fertilization of technological fields, increase in the costs of development of technology and the reduction of the product cycle, have produced a restructuring of the organization of technological activities (Mowery and Rosenberg 1989). One of the main consequences of this restructuring seems to be the growth in the number of inter-firm technological agreements (Chesnais 1988).

The increase in inter-firm cooperation has been accompanied by an intense debate about the role of technological competencies in the establishment of alliances. Cohen and Levinthal (1989) have argued that the acquisition of externally produced knowledge should be accompanied by an increase in the firm's $R \& D$ due to the importance of $R \& D$ in the determination of a firm's absorptive capacity. This hypothesis has been tested in a number of different studies with mixed results (Colombo and Garrone 1996, Arora and Gambardella 1990, Kleinknecht and Reijnen 1992). Richardson (1972) has emphasized the role of asset dissimilarity in the shaping of organization of industry when complementary assets are involved. He has argued that dissimilar assets are unlikely to be internalized and therefore should be acquired through alliances. A series of studies show that most of the agreements on technology are motivated by the need to access complementary assets (Hagedoorn 1993, Mariti and Smiley 1983). The decision to collaborate in technology should then be understood as a strategic choice to avoid high sunk costs. More specialized firms should be more likely to engage in inter-firm agreements while more technologically and productively diversified firms - that hold a wider range of competencies should be more prone to integrate such activities. However, the strategic choice should not be exempted of trust relationships. According to the transaction costs approach, there isn't much difference in this respect between cooperative and pure market transactions.

This paper attempts to contribute to the debate using a database built from patents jointly filed by two or more firms in the European Patent Office. It aims to address issues associated with the substitutive or complementary character of the literature and to the role played by firms' technological competencies and capabilities. The first section is dedicated to the display of the theoretical ideas and the empirical evidence that illuminate the paper. The second section presents 
the data that is going to be used and tries to cover its main limitations. The third section presents the main results of the paper and links them to the main propositions made by the literature on the subject.

\section{THEORETICAL AND EMPIRICAL BACKGROUND}

Evidence for the Growth of Technological Cooperation

Chesnais (1988) has surveyed the literature on technological cooperation and has collected evidence that shows that the number of technological agreements between firms has grown during the 1980's. Hagedoorn and Schakenraad (1990) confirmed this trend for a wide range of modes and motives of agreement. Graphic 1 shows support for these results using data composed by patents jointly filed by two or more firms. It also reveals a stabilization in the number of joint patents in the end of the 80's. This evidence suggests that the 1980's witnessed some transformations in the organization of technological activities. Apart from being carried out in intramural R\&D labs (Mowery 1983, Teece 1988), technological activities appear to be undertaken through external linkages.

Figure 1 - Evolution of Technological

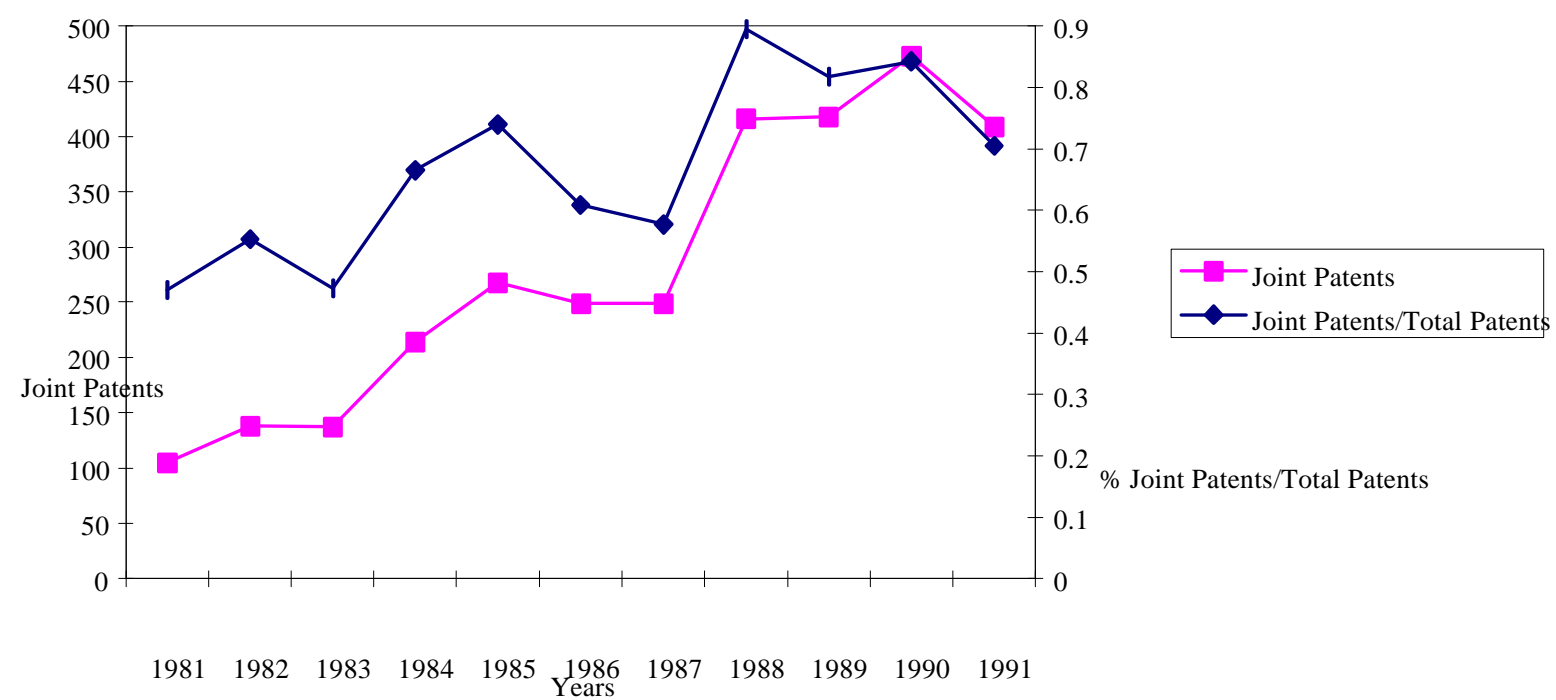

Source: Own manipulation of the Bulletin Database in CD-ROM, 1993 and The European Report on Science and Technology Indicators, 1994.

The number of joint patents is a subsample represented by those patents that were filed by 536 big firms, while the number of total patents is the total sample of the European Patent Office. 
Mowery and Rosenberg (1989) and Chesnais (1988) have argued that the re-organization of technological activities during the 1980's was mainly related to recent developments in technology, such as: (i) the continued growth in development costs; (ii) technological convergence or cross-fertilization of technologies; (iii) shorter product cycles; and (iv) faster rates of technical change. The growth in the R\&D costs implies that the minimum efficient scale of $R \& D$ projects has increased. This is particularly important if the time to profit from the innovation - the product cycle - has been reduced, because the fixed costs of innovation will have to be covered in a shorter period. Technological convergence has demanded firm's competencies to be spread over a greater number of technological fields, that is, the number of technologies that a firm has to deal with has increased. It should be stressed however that none of the listed events implies the total externalization of R\&D laboratories, but solely the level of commitment in sunk costs related to knowledge specific assets.

The Importance of Absorptive Capacity

According to this picture, the choice to follow cooperative strategies could be a consequence of the substitution of technological cooperation for intramural $R \& D$, that is, technological interfirm collaboration can be used to reduce innovation costs through the decline in the need for internalized competencies. Yet, as pointed out by Mowery and Rosenberg (1989), one of the most important drawbacks of cooperation is the under-investment in competencies that may take firms to weaken competitive positions in the long run. This should be important because technological environments are complex and involve a great deal of uncertainty associated with its outcomes and costs. As a consequence, rationality should be bounded and knowledge should be processed for deliberation to take place. Furthermore, as technical knowledge involves tacit characteristics and is cumulative, firms should need to absorb knowledge in order to take decisions about recent developments and to determine what types of knowledge they should contract. Granstrand et al. (1997) and Patel and Pavitt (1994a,b) add some empirical evidence to these observations. They show that big firms' competencies are spread across technical fields outside those where they hold distinctive competencies. Moreover, firms have become increasingly more technologically diversified in recent years. They argue that this should be a consequence of the need to develop knowledge on those technical fields where firms do not act directly, but need to interact with other firms. For the specific case of collaborative agreements, this can be confirmed by case studies that show that in order to absorb knowledge produced outside their boundaries, firms have to develop competencies in the technical fields where cooperation is being used (Granstrand et al. 1992). According to this approach, the new wave of 
technological cooperation has a complementary rather than a substitutive character to intramural $\mathrm{R} \& \mathrm{D}$, in that the increase in the level of cooperation should involve an increase in in-house $\mathrm{R} \& \mathrm{D}$ expenditures.

In a seminal work, Cohen and Levinthal (1989) show that R\&D has indeed two different functions - it is undertaken to generate innovations and/or to increase the firm's absorptive capacity - and therefore it should be considered complementary to external sources of knowledge. They find evidence that greater levels of $R \& D$ are undertaken in those sectors where there is higher degree of systemic and intra-industry spillovers. Colombo and Garrone (1996) test Cohen and Levinthal's (1989) hypothesis for the specific case of cooperation in information technology sectors and find high correlation between the two variables. Arora and Gambardella (1990) analyze four different modes of acquisition of technology for the biotechnology case: inter-firm technological agreements, university-firm collaboration, minority share participation in small high-tech firms, acquisition (more than 50\%) of small high-tech firms. They find that the number of participations of a firm amongst these variables are positively correlated which shows a great level of complementarity between these strategies. Furthermore, using the number of patents in biotechnology as a measure for in-house technological efforts in that area of knowledge, they show that patents are positively correlated - and statistically significant - to the number of interfirm agreements, university-firm links and minority participation, and negatively, though not statistically significant, correlated to acquisitions. Though important, these studies have limited samples, associated with a limited number of sectors. In contrast, Kleinknecht and Reijnen (1992) find no evidence for the confirmation of Cohen and Levinthal's (1989) hypothesis. Using a probit model, they show that the probability of a firm to engage in $R \& D$ cooperation has no relationship with the R\&D intensity of the firm.

The Importance of Asset Specificity, Complementarity and Dissimilarity

Richardson (1972) has focused on the importance of asset complementarity in the organization of industry. According to his arguments, coordination problems may arise when assets are transacted in small numbers, that is, when the demand for a certain asset is associated with specific characteristics so that possible losses from shirking cannot be overcome through alternative market transactions.

The tacit characteristic of technology demands costly pre-contractual interaction between the R\&D laboratory and downstream activities, such as production and marketing, so that technological features and needs can be defined and agreed. Furthermore, the uncertainty 
embedded in these activities may pose some obstacles to the ex ante calculation of costs and rewards of the innovative process and thus ex ante agreements on price may face problems. The demand for a relationship-specific investment transforms an ex ante large numbers bargaining situation into an ex post small numbers negotiation. The complexity of the transaction may even obstruct the calculation of the necessary sunk costs investments what may hinder solutions such as the provision of hostages (Teece 1988).

The agreement on rules to govern ex post pricing may also encounter limitations. Cost plus contracts may encourage the practice of high costs by the hired party demanding monitoring from the contracting party. Yet, monitoring costs may reach very high values. In addition, the exchange of knowledge between the R\&D lab and the manufacturing firms may open room for opportunistic behavior by the supplier that can transfer part of the acquired proprietary knowledge to rival firms. Finally, the tacit and cumulative elements of knowledge produce a lockin situation leaving the contracted party in a better position to undertake following research activity or creating circumstances where the supplier may behave opportunistically like in the correcting of some errors or mistakes that may have arisen from the R\&D activity itself (Teece 1988). Thus, the importance of asset specificity for technological cooperation is that it avoids the undertaking of technological activities through market transactions. The tendency for the internalization of R\&D labs in the first half of this century is one important stylized fact that confirms this type of problem (Mowery 1983).

Dissimilarity of an asset may influence the configuration of technological activities because it affects the degree of difficulty to internalize technological developments. When assets are closely complementary and involve complex or specific transactions, there is need for close coordination. As a consequence, they cannot be freely traded through market transactions. The presence of dissimilarity poses some importance shortcomings for the internalization of the development of the asset. In the case of technology some of the limitations are: (i) the tacit and cumulative character of technology imply the need for in-house development of the competencies that induce high $\operatorname{costs}^{1}$ with high level of irreversibility; and (ii) rapid changing technological environments may ask for fast answers while the building of technological competencies may be quite slow.

Firms may deal with dissimilarity in distinct ways. They may buy it outside, acquire it through cooperation or simply internalize it. The propensity to internalize dissimilar assets should be a function of two different features: (i) the level of risk aversity of the firm to invest in sunk costs;

1 There is a great number of consequences of this problem: (i) investment in human capital is specific involving sunk costs; and (ii) there is the risk of the firm losing coherence in its technology base. 
and (ii) the diversity of its productive and technological base. In the first case, apart from individual and managerial characteristics, there may be some role played by wealth effects associated with firm size. In the latter case, a firm's level of specialization is the main determinant.

Empirical findings confirm the relevance of complementarity. Hagedoorn and Schakenraad (1990) have found that technological complementarity is the most important motive for the undertaking of joint $\mathrm{R} \& \mathrm{D}$ in the three fast changing technology fields they investigate, followed by the reduction of innovation $\operatorname{span}^{2}$, that is, the access to dissimilar knowledge and the answer to a fast moving environment. In addition, Hagedoorn and Schakenraad (1990) show that most cooperative agreements are related to strategic objectives rather than cost economizing ones. Mariti and Smiley (1983) have identified technological complementarity as the most important motive for firms' engagement in cooperative arrangements (including non-technological). Rocha (1995) has shown, using a joint patent database, that technological cooperation has mainly occurred between partners that mainly belong to different productive sectors and therefore that hold dissimilar competencies.

\section{Trust and Nationality}

Still, a transaction cost theorist would argue that there isn't any great difference between technological collaboration and market transaction in terms of the hazards that one can encounter in either modes of transacting assets. Therefore, he would hold that one out of two beliefs should be underlying the above developed approach: (i) contracts in collaborative arrangements are selffulfilling; or (ii) there is always a contractual design to overcome hazard problems in partnerships.

A self-enforcing agreement to take place would require "a sequence of transactions over time such that ending date is unknown and uncertain" Williamson (1985:169). ${ }^{3}$ The infinite horizon approach has been taken by many studies dealing with collusive behavior in the product market (Jacquemin and Slade 1989). According to these studies an infinitely repeated non-cooperative game may have a cooperative solution. Williamson (1985:169) avoids this kind of arguments because "the transactions I consider can be (indeed, normally are) finite". Kreps (1990) suggests an alternative vision. He argues that the fundamental role of the firm is to be the long-lasting party in a sequence of short run (finite) transactions. It should then hold a reputation that ensures the correct fulfilling of incomplete contracts. He therefore states that the role of corporate culture is to act as a commitment for the maintenance of contractual clauses, that is, for not acting opportunistically. As a possible extension of his theory, Kreps (1990) proposes to analyze a

\footnotetext{
2 Together they answer for more than $70 \%$ of the events in each technological field.

3 Quoting Lester Telser.
} 
situation where the two parties are long-lived. Their corporate culture or the reputation in sustaining certain kinds of behavior is their ex ante commitment for the agreement to take place. In this case, another type of influence may be important: corporate culture or held reputation.

Nonetheless, the measurement of the effect of corporate culture would be very difficult. Here, it is proposed that nationality may gather some of the characteristics of corporate cultures. Lazonick (1991) states that there are some important differences between the managerial capitalism, practiced in the US and spread across many Western economies, and the collective capitalism, present in Japan. The distinguishing factor of managerial capitalism would be the separation between the management and the ownership and heavy investments in managerial structure, while the distinguishing factors of the collective capitalism would be: (i) the organizational integration of a number of different firms; (ii) long run links between employees and the enterprise; and (iii) the State cooperation. Caves (1989) surveying the literature on firm behavior registers also some important international differences. He calls attention for differences in firm organization between French corporate groups and North-American diversified firms. French corporate groups have weaker ownership links and their control is maintained through interlocking directorate rather than strict administrative linkages. He also argues for the differences in Japanese firm organization, such as the keiretsu. Imai and Itami (1984) argue for the relevance of the differences of market and organization penetration between Japanese and American industrial structures. In this sense, it would be licit to use nationality of a generalization for certain corporation practices.

Williamson (1985) has argued that to avoid cheating in agreements some kind of commitment, such as the provision of hostages, from transacting parties may be necessary. The literature on technological cooperation is rich in works trying to relate modes of cooperation to technological requirements for the transaction. Contractor and Lorange (1988) relate the types of incentives that different modes of collaborative arrangements have to the level of dependence required in the transaction. Arora and Gambardella (1990) show that each type of cooperative agreement may be associated with different requirements of knowledge transference or sharing. According to this line of work, there is a vast type of contractual arrangements that can be regarded as a settlement for the carrying out of the collaborative arrangement. Our database - as it will be clear in the next section - cannot account for different contractual situations. Therefore, the rather cynical view that for each specific situation there is a different contractual arrangement will be adopted in this paper or, at least, that the probability of adapting contracts to technological requirements doesn't vary across firms. 
It should be acknowledged that nationality involves other characteristics rather than trust. Levels of firm productive and technological specialization vary across nationalities. Firm size, anti-trust legislation and general legal environment also may differ across countries. Therefore, nationality may be capturing a lot more effects than corporate culture.

\section{METHODOLOGY}

\subsection{The Variables}

The dependent variable

Two types of data are normally used in the study of technological cooperation. Information is either obtained from surveys and questionnaires applied to firms (Mariti and Smiley 1983 and Kleinknecht and Reijnen 1992) or from news on agreements publicized in the specialized press (Ricotta and Mariotti 1986 and Hagedoorn and Schakenraad 1990). All these data sources present important shortcomings and are biased in different ways. ${ }^{4}$ This paper attempts to add knowledge on technological alliances by using an alternative indicator composed by patents jointly filed by the firm with one or more firms (in the European Patent Office) divided by the total number of patents filed by the firm as a measure of the propensity to cooperate.

The use of patents to measure technological activity has some important drawbacks: (i) smaller firms have greater propensity to patent; (ii) sector and technologies differ in their propensity to patent; (iii) the presence of a firm in a market covered by a specific patent office affects its propensity to patent. The greater the presence of a firm is, the greater its propensity to patent should be; and (iv) the value of patents have greater variability. One can also pose some further problems in the use of patents as an indicator of cooperation: (i) it does not capture noninnovative technological cooperation. Therefore, efforts such as technology transfer and crosslicensing will remain out of the analysis; (ii) it does not perform uniformly across different modes of cooperation. Joint ventures' contributions should be largely underestimated by the indicator, due to the fact that they may be filed in the name of the joint venture. In this case, they were not captured by the patent search; (iii) it is mainly a measure of output, so it can underestimate cooperative inputs that are not turned into patents; and (iv) it may capture some effects that do not result from cooperative relationships, such as the use of joint patents as hostage for the establishment of long term cooperation in productive activities. 
Unlikely most of the literature on technological cooperation that uses the number of agreements as a measure of intensity of cooperation and test it against the R\&D intensity (Colombo and Garrone 1996), this paper uses a relative variable - joint patents divided by total patents - as a measure of the propensity to cooperate. Some problems may arise when an absolute variable is tested against a relative variable. Firms with greater levels of $R \& D$ expenditure may cooperate more though in lower proportion than less R\&D intensive firms. Bigger firms may have greater linkages than smaller ones and be less intensive in technological cooperation. Though Colombo and Garrone (1996) have their own reasons for not engaging in this debate, they stress that it would be useful to find an alternative way to measure the propensity to cooperate. ${ }^{5}$ Their main suggestion is the use of the rate of the number of agreements divided by R\&D expenditure. However, the use of the rate of joint patents to the amount of R\&D expenditures would cause problems, due to uneven patenting and R\&D propensities across sectors. ${ }^{6}$ In contrast, the use of the rate of joint patents to total patents is useful to control for some of the above mentioned biases. It may correct for differences in the patenting propensity of firms of different nationality, size and sector.

\section{Dissimilarity and Absorptive Capacity}

As traditionally used in the literature, the firm's absorptive capacity will be measured by the $\mathrm{R} \& \mathrm{D}$ to sales rate.

Dissimilarity will here be approached in three different ways. First, one should expect the probability of an asset being dissimilar to the firm's productive base to be a positive function of the level of the firm's technological specialization. The greater the firm's level of specialization, the higher the level of cooperation should be. Technological specialization is here measured by the rate of patenting in the firm's main sector of activity divided by the total number of patents. However, as there may be differences in technology opportunities across sectors and in the propensity to patent of technologies that have different importance levels across sectors, sectoral dummies should be used.

The probability of the occurrence of asset dissimilarity should also be an inverse function of the firm's level of productive specialization. This could be an inverse function of the level of productive integration of the firm. The literature has used the rate of total added value to total

5 '(U)sing a 'relative' variable such as the ratio of the number of agreements to R\&D expenses or to firms sales instead of TCA's (total cooperative agreements) to capture firm's propensity for cooperation would partially prevent us from entering the methodological debate that is our main concern" (Colombo and Garrone 1996:928)". 6 When $\ln$ Patents are regressed against $\ln R \& D$, the $R^{2}=0.34$, the coefficient is positive and significant at $0,0001 \%$. 
gross output. Unfortunately, data at the firm level was not available. An alternative measure used in this paper as a proxy for the level of integration is the sectoral rate of total added value to total gross output at the national level. Some biases may therefore arise: (i) multinational firms that participate in many economies will be represented by their home country's data; and (ii) some firms may have activities outside their main sector of production.

A third variable used to measure the effect of asset dissimilarity on its propensity to cooperate is the firm's size represented by its total sales. Bigger firms are more likely to be more technologically diversified and therefore to easily access complementary technologies (Patel and Pavitt 1994). Some side effects may also be captured by this variable. Bigger firms are more likely to invest in sunk costs associated with technology and should have easier access to financial funds.

\subsection{Data Sources}

Data was obtained for 81 firms - 31 Japanese, 23 European and 27 North-American - with activities in high technology sectors (see table 1). Data on joint patents filed by two or more firms in the European Office were obtained by the Bulletin CD-ROM of the European Patent Office for the years 1988 to 1992. Patents were selected by the firm name. Patents that were filed in the name of the firm's subsidiaries were also included. Joint patents between parent and subsidiaries or subsidiaries of the same group - according to the Who Owns Whom criteria - were excluded. As a consequence, there should be no ownership linkages between firms jointly patenting in the database and the firms are not expected to have patents filed by subsidiaries that are not part of the database. 
Table 1

Main Characteristics of the Firms in the Database

\begin{tabular}{lrrrr}
\hline \multicolumn{1}{c}{ Variable } & \multicolumn{1}{c}{ Mean } & Standard Deviation & Minimum & Maximum \\
\hline$R \& D$ Intensity & 6.89 & 3.3950 & 1.12 & 15.56 \\
Sales $^{*}$ & 16365.58 & 19049 & 1412 & 101916 \\
Joint Patents & 16.96 & 21.56 & 1 & 99 \\
Total Patents & 1070.85 & 1189.61 & 19 & 5529 \\
& & & & \\
\hline
\end{tabular}

Source: European Commission, The European Report on Science and Technology Indicators, Luxembourg, OOPEC, 1994. The number of joint patents is obtained by own manipulation of the Bulletin Database in CD-ROM, 1993.

"Billions of ECU's for 1992.

Data on the total number of patents and patents in the firm's main sector of activity between 1988 and 1992 and R\&D data for 1992 were obtained from European Commission, The European Report on Science and Technology Indicators, Luxembourg, OOPEC, 1994. Data on sectoral rate of value added to gross production for each country was obtained from OECD, The OECD Input-Output Database, Paris, 1994. Companies were classified according to the nationality of its parent firm.

\section{EMPIRICAL ANALYSIS}

\subsection{The Model}

According to the variables that have been pointed out above, one can define a model in which PROPCOOP = f(RDINT, SIZE, PRODSPEC, TECHSPEC, NATION $)$, or

$$
\begin{gathered}
\mathrm{LN} \text { PROPCOOP }=\mathrm{LN} \alpha+\beta \mathrm{LN} \text { RDINT }+\gamma \mathrm{LN} \mathrm{SIZE}+\varphi \mathrm{LN} \text { PRODSPEC }+\lambda \mathrm{LN} \\
\text { TECHSPEC }+\mu \text { EUDUM }+\nu \text { JPDUM }
\end{gathered}
$$

where PROPCOOP is a firm's propensity to cooperate, represented by the number of joint patents divided by the total number of patents filed between 1988 and 1992, RDINT is the firm's R\&D intensity in 1992, SIZE is represented by sales in 1992, PRODSPEC is the firm's productive specialization here associated with a proxy measure denoted by the firm's national sector rate of added value to gross production (LN AVGO), TECHSPEC is the firm's level of technological specialization expressed by the number of patents in its main sector of technological activity divided by its total number of patents between 1988 and 1992. Nationality is represented by two 
dummies, EUDUM for European firms and JPDUM for Japanese firms. Sectoral dummies are introduced in those equations where TECHSPEC is present. 
Table 2

OLS Regressions - Dependent Variable LN(number of joint patents/total patents)

\begin{tabular}{|c|c|c|c|}
\hline Variable & (1) & (2) & (3) \\
\hline \multirow[t]{2}{*}{ Constant } & 10,300 & 5,41 & $22,633^{\#}$ \\
\hline & $(1,597)$ & $(1,64)$ & $(6,629)$ \\
\hline \multirow[t]{2}{*}{ LNRDINT } & $-0,229$ & $-0,01$ & $-0,156$ \\
\hline & $(-0,689)$ & $(-0,04)$ & $(-0,459)$ \\
\hline \multirow[t]{2}{*}{ LNSIZE } & $-0,273^{+}$ & $-0,31^{*}$ & $-0,314^{*}$ \\
\hline & $(-1,896)$ & $(-2,82)$ & $(-2,159)$ \\
\hline \multirow[t]{2}{*}{ LNTECHSPEC } & 0,250 & & $0,395^{+}$ \\
\hline & $(1,063)$ & & $(1,720)$ \\
\hline \multirow[t]{2}{*}{$L N A V G O$} & $-2,902^{+}$ & $-1,49^{*}$ & $-6,232^{\#}$ \\
\hline & $(-1,728)$ & $(-2,45)$ & $(-7,916)$ \\
\hline \multirow[t]{2}{*}{ CHEMICAL } & $-0,141$ & & $0,335^{*}$ \\
\hline & $-0,289$ & & $(0,750)$ \\
\hline \multirow[t]{2}{*}{ PHARMA } & 1,098 & & $2,533^{*}$ \\
\hline & 1,214 & & $(3,975)$ \\
\hline \multirow[t]{2}{*}{ ELECTRO } & 0,595 & & $1,799^{*}$ \\
\hline & 0,812 & & $(3,616)$ \\
\hline \multirow[t]{2}{*}{ COMPUTER } & 0,763 & & $1,752^{*}$ \\
\hline & $(0,921)$ & & $(2,703)$ \\
\hline \multirow[t]{2}{*}{$E U D U M$} & 0,289 & 0,21 & \\
\hline & $(0,927)$ & $(0,82)$ & \\
\hline \multirow[t]{2}{*}{$J P D U M$} & $1,282^{*}$ & $1,52^{\#}$ & \\
\hline & $(2,377)$ & $(4,94)$ & \\
\hline$R$-squared & 0,61 & 0,58 & 0,57 \\
\hline Adjusted R-squared & 0,54 & 0,55 & 0,51 \\
\hline$F$ & $9,05^{\#}$ & $20,48^{\#}$ & $9,99^{\#}$ \\
\hline$N$ & 69 & 81 & 69 \\
\hline
\end{tabular}

t-statistics in parenthesis

${ }^{+}$Significant at the $10 \%$ level

*Significant at the $5 \%$ level

"Significant at the $1 \%$ level 


\subsection{The Results}

Table 2 shows the results of the regressions. All equations have acceptable R-square and F levels. Equation (1) has the presence of all the variables introduced in the model. It however does not include firms outside science-based and motor vehicles sectors. Equation (2) introduces firms that belong to specialized-suppliers (machinery, rubber and instruments) and other scale-intensive (food and glass) sectors, data on technological specialization was not available. Equation (3) excludes the nationality dummies and shows some important differences in the behavior of the other variables.

\section{$\underline{\text { Absorptive Capacity }}$}

The R\&D intensity variable has a negative sign in all equations, though it is not significant in any of them. There seems to be no evidence to support the hypothesis that a firm has to increase its level of R\&D in order to acquire externally produced knowledge. On the contrary, the general results seem to show that technological cooperation is not influenced by the firm's R\&D intensity. ${ }^{7}$ It should be stressed that cooperation is not totally external to the firm's activities and thus it should be understood as a particular case. One should also be careful to make any further assertion due to the characteristics of the sample. The paper gathers data only on big, technology intensive firms (see table 1). There could be a threshold R\&D level for firms to absorb external knowledge. ${ }^{8}$ In this case, the technological cooperation would increase with R\&D intensity when the level of R\&D was very low until it reached intermediary intensity.

\section{Dissimilarity and Specialization}

Firm size shows a negative sign and is significant in all equations, suggesting that smaller firms are more likely to cooperate than bigger firms. This result was predicted by the examination of the literature. Smaller firms tend to be productively and technologically less diversified and they should face greater obstacles to access financial funds and greater reluctance to invest in sunk costs. This also may partially explain the greater propensity to patent of smaller firms - which suggested the existence of decreasing returns to R\&D (Bound et al. 1984) - by showing their

\footnotetext{
7The running of equations without weighting the number of joint patents by the total number of patents show a positive non-significant sign. The only result positive and significant occurs when the total amount of R\&D is not divided by sales and there is no control for firm size. Moreover, when the endogenous variable is measured by joint patents dividded by total R\&D expenditures instead of total patents (they are controlled for sectoral differences to avoid differences in the patenting propensity), the coefficient is negative and significant. However, all these regressions present serious problems of biases that should be avoided (in these cases, most sectoral variables are significant).

8Though the coefficient in the test of a quadratic form showed no significance.
} 
greater reliance on externally produced knowledge at least in the case of technological cooperation.

In the two equations where the technological specialization measure is included, it holds a positive sign, though it is only significant when the equation is not controlled for nationality. This shows that the level of specialization may be slightly affecting the firm's propensity to cooperate technologically. Technological cooperation may be an alternative strategy to overcome constraints of narrow competence formation. This result may oppose some of the literature that state the need for firms to be technologically diversified in order to access complementary assets (Granstrand et al. 1997). Some remarks should however be made in this respect. First, the analysis here undertaken does not fully assess a firm's technological base. Some of the more specialized firms may still hold some technological competencies in those technical fields where they are cooperating. Furthermore, tests should still be held with other measures of technological specialization in order to have a robust result. Some further work has still to be done in this respect. ${ }^{9}$ Second, not all technological cooperation may involve the absorption of knowledge. Some of the firms in the sample may be suppliers of inputs to other firms and in this respect their greater technological specialization may be an important asset, though they still need some information on the specification of the product to be produced.

The sectoral rate of added value to total production (LNAVGO) has a negative and significant sign in all equations. As this variable is a proxy for the level of integration of the firm, it is negatively correlated to the level of productive specialization. Therefore, the result shows that more productive specialized sectors tend to cooperate more than those sectors where firms are in average more integrated. There is some evidence to support the idea that firms that adopt lean production strategies are more inclined to cooperate. The higher coefficient in equations (2) and (3) demonstrate also that there are important differences in the level of specialization across countries.

9A more thoroughly analysis comparing the technical fields where firms patent jointly with other firms with those where they hold competencies should be done. 
Figure 2 - Percentage of Intra-sectoral Patents

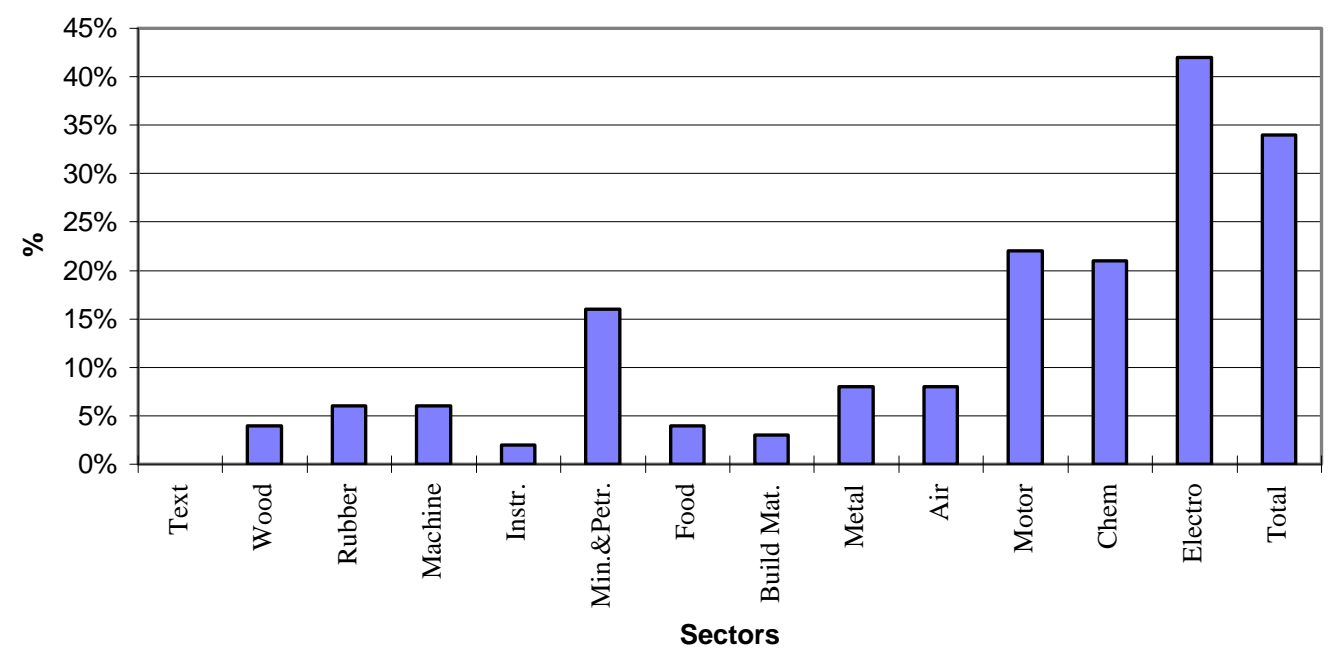

Source: Own manipulation of the Bulletin Database in CD-ROM, 1993 and The European Report on Science and Technology Indicators, 1994.

The results on the levels of productive and technological specialization and on firm size seem to confirm the hypothesis of the importance of the acquisition of complementary and dissimilar assets for the undertaking of cooperation. More specialized, smaller firms that cannot internally access some knowledge intensive asset because either they lack competencies or they are not sufficiently productively diversified show a greater propensity to cooperate than more diversified, bigger firms. Figure 2 shows that most of the inter-firm technological linkages involve partners that belong to different productive sectors at a very high level of aggregation. ${ }^{10}$ These partners are most likely to hold dissimilar competencies. ${ }^{11}$ Furthermore, the analysis of the firms involved in most of the intra-sectoral alliances reveals that they are mainly associated with vertical relationships. In the motor vehicle sector, for instance, auto part producers establish linkages with auto assemblers; producers of electrical cables have connections with firms in the telecommunications sector, etc. Furthermore, Rocha (1997) found a relationship between intersectoral technology flows and the technological partnerships described by patents. These features demonstrate that the location of firms in the input-output matrix may be an important influence on the determination of the choice of partners. As firms become more productively specialized, they may need greater level of communication with supplier firms. Therefore, the need to access

10 Data on joint patenting activity of 536 firms belonging to 14 different two-digit sectors. Joint patent among firms with ownership relations were eliminated. It should be emphasized that the lower the level of aggregation is, the more likely it should be to find that partner firms produce in different sectors.

11 This is a result found by Patel and Pavitt (1994) and Jaffe (1986). 
dissimilar competencies in more specialized firms may be an important element in the determination of the level of technological cooperation.

\section{Nationality}

The European dummy is not significant, though positive, the Japanese dummy shows a positive and significant sign in both equations where it is included. Japanese firms seem to be more likely to cooperate than Western ones. Similar results have been achieved in a number of case studies (Hamel 1991 and Chesnais 1988) though the majority of the analysis undertaken using big databases show no particular tendency for bigger firms to have higher levels of cooperation, due to biases in their information sources (Chesnais 1988, Hagedoorn 1995). Thus, the result does not present great novelty.

The literature on technological cooperation is very rich in justifications for the greater level of cooperation in Japan. Chesnais (1988) justifies it by three main reasons: (i) the existence of business groups in Japan; (ii) the State interference in the formation of inter-firm technological alliances; and (iii) the very early recognition in Japan of the advantages of cross-sectoral horizontal cooperation.

Cooperation inside business groups does not seem to be a useful explanation for the results here obtained. Using information for joint patenting activities of 139 Japanese firms, Rocha (1995) has concluded that only about $15 \%$ of the total domestic partnerships involved firms inside the same business group. The state intervention should also provide limited explanation. Technological cooperation stimulated by the Japanese government take the form of consortia (Mowery and Rosenberg 1989 and Chesnais 1988), that are usually associated with a large number of firms. Nonetheless, less than $5 \%$ of the total patents in the database were filed by more than two firms. The third reason given by Chesnais (1988), still requires refinement.

Aoki (1988) adds some insights to the explanation of Japanese behavior. He claims that the ownership structure of the Japanese firm - Bank and employee control - has many consequences on the functioning of firms. One of these differences is that the protection of incumbent employee's interests in Japanese firms impose restrictions for the hiring of new labor. As a consequence, Japanese firms spin-off a large number of labor intensive activities. One outcome of this spinning-off is the greater specialization inside the same production chain. In table 2, where the nationality dummies are not included there is an increase in the elasticity of the rate of added value to gross production. This is confirmed in table 3 that shows that the AVGO rate is lower in Japan than in any other country/region. Table 3 also demonstrates that Japanese firms are 
generally smaller than European and North-American firms. This suggests that Japanese firms are less integrated and therefore need to rely more on outside built capabilities and on outside supply of specific assets. The need to correctly inform parties may induce cooperation.

Table 3

National Differences in Key Variables

\begin{tabular}{|c|c|c|c|c|c|c|}
\hline Nationality & Variable & Mean & Standard Deviation & Minimum & Maximum & Cases \\
\hline \multirow[t]{5}{*}{ Japan } & $R \& D$ Intensity & 6.67 & 2.79 & 1.12 & 13.48 & 31 \\
\hline & Sales & 14831.12 & 15604.67 & 1488.24 & 54924.48 & 31 \\
\hline & Techspec & 0.47 & 0.27 & 0.04 & 1.00 & 27 \\
\hline & Avgo & 31.53 & 6.64 & 21.32 & 42.08 & 31 \\
\hline & Patents & 918.87 & 1064.82 & 28.00 & 3224.00 & 31 \\
\hline \multirow[t]{5}{*}{ Europe } & $R \& D$ Intensity & 6.96 & 4.11 & 1.57 & 15.57 & 23 \\
\hline & Sales & 16946.82 & 13763.97 & 2194.92 & 50035.44 & 23 \\
\hline & Techspec & 0.59 & 0.22 & 0.13 & 0.93 & 21 \\
\hline & Avgo & 38.87 & 6.88 & 27.18 & 52.17 & 23 \\
\hline & Patents & 1374.48 & 1542.24 & 158.00 & 5529.00 & 23 \\
\hline \multirow[t]{5}{*}{$U S A$} & $R \& D$ Intensity & 7.57 & 3.31 & 2.83 & 13.66 & 27 \\
\hline & Sales ${ }^{*}$ & 19132.24 & 25788.56 & 1411.80 & 108916.08 & 27 \\
\hline & Techspec & 0.43 & 0.22 & 0.10 & 0.75 & 21 \\
\hline & Avgo & 43.21 & 6.16 & 30.04 & 55.22 & 27 \\
\hline & Patents & 986.70 & 957.64 & 19.00 & 3964.00 & 27 \\
\hline
\end{tabular}

Source: R\&D Intensity, Sales, Technological Specialization and Total Patents are obtained European Commission (1994), European Report on Science and Technology Indicators, OOPEC, Luxembourg. Added Value to Gross Output ratio (AVGO) is obtained from OECD (1994) The OECD Input-Output Database, New York.

*Values in billions of 1992 ECUs. 
Second, Aoki (1988) emphasizes the role played by labor market rigidities in Japanese firms in the establishment of cooperation. According to him, Japanese firms are not allowed to hire midcareer scientists because they would be breaking organizational rules for contracting labor. ${ }^{12}$ Therefore, the acquisition of competencies in fast moving technological fields would depend either on slow young scientists hiring or on external sources or firm acquisition. Cooperation should be a solution for this kind of dilemma. This should be represented by a greater technological specialization of Japanese firms. Although the TECHSPEC variable in table 2 is significant only in equation (3) where there is no nationality dummy, table 3 shows that, though Japanese firms have greater level of specialization than North-American firms, European firms appear to be more specialized. This result could however be biased by the sectoral composition of the national samples of firms.

\section{CONCLUSIONS}

Two sets of conclusions may be extracted from the analysis carried out above. First, there are those conclusions associated to the resource-based theory of the firm and the held hypotheses on technological intensity and asset complementarity. The database here used shows no support for the hypothesis that greater R\&D intensity is needed when firms are to absorb external knowledge produced through inter-firm alliances. However, as has been stressed above, one should be very careful with those results due to the number of firms and the biases in the sample used in this paper. Some further work is still required. Moreover, a firm's level of specialization may influence its degree of cooperation. In this case, the intensity of cooperation seems to be higher in smaller, technologically less diversified and productively specialized firms.

The need to acquire complementary and dissimilar competencies appears to be an important motive for cooperation. These issues show that though a firm's intensity of R\&D is not related to its level of cooperation, the composition of its competencies and capabilities should play an important role in the determination of its access to extra-mural produced knowledge. Though they do not directly challenge conclusions on the importance of the development of specialized knowledge in those technical fields where the firm should acquire externally produced knowledge, the results show that some further work should be carried out comparing the competencies held

12Either associated with corporate culture and the discipline in intra-firm labor market or with inter-firm agreements against raids over each other's labor force. 
by the firm with the technical fields where cooperation takes place, so the substitutive character of cooperation for in-house R\&D can be correctly assessed.

The negative sign of firm size and of the rate of added value to gross output coupled with the technological specialization and $R \& D$ results seem to indicate that technological cooperation is an important alternative strategy for smaller more specialized firms to overcome scale disadvantages that may arise from economies of scope and the cross-fertilization of technological fields that have appeared in recent years. This is probably the strongest implication of the paper: technological cooperation may be associated with lean production strategies

The second set of conclusions refers to international differences in the propensity to cooperate. Japanese firms appear to have a higher level of technological cooperation than Western firms. This can be partially explained by differences in the industrial and intra-firm organization. First, Japanese firms appear to be less integrated; second, they seem to be more productively specialized. This result is suggested to be consequence of the idiosyncrasies of ownership control in the Japanese economy. Moreover, it does not deny the existence of some degree of path dependence in the structuring and trust relations of technological alliances. This theme should however be object of greater investigation. 


\section{REFERENCES}

1. AOKI, M. (1988) Information, Incentives and Bargaining in the Japanese Economy. Cambridge, Cambridge University Press.

2. ARORA, A. and GAMBARDELLA, A. (1990) Complementarity and External Linkages: The Strategies of the Large Firms in Biotechnology. Journal of Industrial Economics, XXXVIII, 4, 361-79, June.

3. BOUND, J; CUMMINS, C.; GRILICHES, Z.; HALL, B. and JAFFE, A. (1984) Who does R\&D and who patents? In Griliches, Z. (ed.) R\&D, Patents, and Productivity, Chicago, The University of Chicago Press.

4. CAVES, R. (1989) International Differences in Industrial Organization. In Schmanlensee, R. and Willig, R. (eds.) Handbook of Industrial Organization, North-Holland, Amsterdam.

5. CHESNAIS, F. (1988) Technical Co-operation Agreements between Firms. STI Review, 4, p. 51-119.

6. COHEN, W. and LEVINTHAL, D. (1989) Innovation and Learning: The Two Faces of R\&D. The Economic Journal, 99, 569-596.

7. COLOMBO, M. and GARRONE, P. Technological cooperative agreements and firm's R\&D intensity. A note on causality relations. Research Policy, 25(6), 923-32, 1996.

8. CONTRACTOR, F. and LORANGE, P. Why Should Firms Cooperate? In Contractor, F. and Lorange, P. Cooperative Strategies in International Business. New York, Lexington Books, 1988.

9. DOSI, G. The nature of innovative process. In Dosi et al. (eds.) Technical Change and Economic Theory. Pinter, London, 1988.

10. EUROPEAN COMMISSION (1994), The European Report on Science and Technology Indicators, Luxembourg, OOPEC.

11. EUROPEAN PATENT OFFICE (1993) Bulletin Patent Database in CD-Rom. European Patent Office, Vienna.

12. FORAY, D. (1991) The secrets of industry are in the air: Industrial cooperation and the organizational dynamics of the innovative firm. Research Policy, vol. 20, 393-405.

13. GRANSTRAND, O.; BOHLIN, E.; OSKARSSON, C.; and SJÖBERG, N. (1992) External technology acquisition in large multi-technology corporations. R\&D Management, 22(2), 111133.

14. GRANSTRAND, O.; PATEL, P.; PAVITT, K. (1997) Multi-technology corporations: why they have "distributed" rather than "distinctive core" competencies. Mimeo, Brighton, March.

15. GRILICHES, Z. (1990) Patent Statistics as Economic Indicators: a survey. Journal of Economic Literature, vol. XXVIII, 1661-707.

16. HAGEDOORN, J. and SCHAKENRAAD, J. (1990) Interfirm Partnerships and co-operative strategies in core technologies. In Freeman, C. and Soete, L New Explorations of Technical Change, Pinter Publishers.

17. HAMEL, G. Competition for Competence and Inter-Partner Learning within International Strategic Alliances. Strategic Management Journal, 12, 83-103, 1991.

18. IMAI, K. K. and ITAMI, H. (1984) Interpenetration of Organization and Market. International Journal of Industrial Organization, 2, 285-310.

19. JACQUEMIN, A. and SLADE, M. (1989) Cartels, Collusion and Horizontal Mergers. In Schmanlensee, R. and Willig, R. (eds.) Handbook of Industrial Organization, North-Holland, Amsterdam.

20. JAFFE, A. Characterizing the 'Technological Position' of Firms, with Application to Quantifying Technological Opportunity and Research Spillovers. Research Policy, 18, 87-97, 1989. 
21. KREPS, D. (1990) Corporate Culture and Economic Theory. In Alt, J. and Shapsle, K. (eds.) Perspectives on Positive and Political Economy, Cambridge University Press Cambridge.

22. LANGLOIS, R. (1992) Transaction-cost Economics in Real Time, Industrial and Corporate Change 1(1).

23. LAZONICK, W. (1991) Business Organization and the Myth of the Market Economy, Cambridge, Cambridge University Press.

24. MARITI, P and SMILEY, R. (1983) Co-operative Agreements and the Organization of Industry. Journal of Industrial Economics. XXXI, 4, June.

25. MONTEVERDE, K. and TEECE, D. (1982) Supplier Switching Costs and Vertical Integration in the Automobile Industry. Bell Journal of Economics, 13 (1), 206-13.

26. MOWERY, D. (1983) The relationship between intrafirm and contractual forms of industrial research in American manufacturing, 1900-1940. Explorations in Economic History, 20, p. 351-74.

27. MOWERY, D. and ROSENBERG, N. (1989) Technology and the Pursuit of Economic Growth. Cambridge University Press, Cambridge.

28. NELSON, R. and WINTER, S. (1982) An Evolutionary Theory of Economic Change. Cambridge, The Belknap Press.

29. OECD (1994) The OECD Input-Output Database, New York.

30. PATEL, P. and PAVITT, K. (1994a) Technological Competencies in the World's Largest Firms: characteristics, constraints and Scope for Managerial Choice. SPRU, STEEP discussion paper $n$. 13 .

31. (1994b) The continuing, widespread (and neglected) importance of improvements in mechanical technologies. Research Policy, 23, 532-45.

32. PAVITT, K. (1988) Uses and Abuses of Patent Statistics. In van Raan, A. (ed.), Handbook of Quantitative Studies Science and Technology, Amsterdam, North Holland.

33. REINGANUM, J. (1989) The Timing of Innovation: Research, Development and Diffusion. In Schmanlensee, R. and Willig, R. (eds.) Handbook of Industrial Organization, NorthHolland, Amsterdam.

34. RICHARDSON, G. B. (1972) The Organization of Industry. The Economic Journal, 82, 88396

35. ROCHA, F. (1995) Competências Tecnológicas e Cooperação Inter-firma: Resultados da Análise de Patentes Depositadas em Conjunto. (in Portuguese) Rio de Janeiro, IEI/UFRJ, $\mathrm{PhD}$ thesis.

36.

(1997) Sectoral Patterns of Technological Cooperation. Rio de Janeiro, Universidade Federal Fluminense, mimeo.

37. TEECE, D. (1982) Towards an Economic Theory of the Multiproduct Firm. Journal of Economic Behavior and Organization, 3, March, 39-63.

38. (1986) Profiting from technological innovation: Implications for integration, collaboration, licensing and public policy. Research Policy, vol. 15, 285-305.

39. (1988) Technological Change and the Nature of the Firm. In Dosi et al. (eds.) Technical Change and Economic Theory. Pinter, London.

40. WILliAMSON, O. (1985) The Economic Institutions of Capitalism. The Free Press, New York. 